\title{
Control of mycotoxigenic fungi with microcapsules of essential oils encapsulated in chitosan
}

\author{
Rocio Elizabeth VILLEGAS-RASCÓN ${ }^{1}$, Ana Karenth LÓPEZ-MENESES ${ }^{1}$, Maribel PLASCENCIA-JATOMEA ${ }^{1}$, \\ Octavio COTA-ARRIOLA ${ }^{2}$, Griselda Macrina MORENO-IBARRA ${ }^{3}$, Lucía Guadalupe CASTILLÓN-CAMPAÑA3, \\ Reyna Isabel SÁNCHEZ-MARIÑEZ ${ }^{3}$, Mario Onofre CORTEZ-ROCHA ${ }^{1 *}$
}

\begin{abstract}
Aspergillus and Fusarium are the fungi genera most frequently isolated from cereal grains and other commodities. They are capable of producing mycotoxins, which can affect the human and animal health. Synthetic fungicides have been used to control these fungi, nevertheless, they have acquired resistance and other alternatives are necessary since they now need higher amounts. Therefore, the aim of this study was to evaluate the efficacy of cinnamon, clove and thyme essential oils (EOs) alone and encapsulated in chitosan on the radial growth, spore germination and mycotoxin production by Fusarium verticillioides and Aspergillus parasiticus. The composition of the EOs was determined by gas chromatography mass spectrometry (GC-MS). EOs inhibited radial growth and spore germination of both fungal species better than when they were encapsulated, plus, they reduced mycotoxin production. The major components were eugenol in cinnamon and clove EO (70 and $63 \%$, respectively) and 2-methyl-5-(1-methyethyl)-phenol (46.2\%) in thyme EO. The microparticles with clove and thyme EO showed good surface charges, higher than $+30 \mathrm{mV}$ and their average size for the three types of microparticles was about $750 \mathrm{~nm}$. Our findings suggest that EOs both alone and encapsulated in chitosan have a fungistatic effect on Fusarium verticillioides and Aspergillus parasiticus.
\end{abstract}

Keywords: aflatoxins; fumonisins; radial growth; spore germination.

Practical Application: Use of essential oils in chitosan microparticles to avoid fungal growth and to reduce the mycotoxin production.

\section{Introduction}

Pathogenic and toxigenic fungi of the Aspergillus and Fusarium genera usually contaminate cereal grains and other commodities in the field and storage. These fungi have the ability to produce mycotoxins and thus to reduce the commercial and nutritional value of the products. There are more than 300 mycotoxins, being aflatoxins and fumonisins among the most commonly isolated (Zhao et al., 2015). Synthetic fungicides are used in the field or in storage facilities mainly to control these fungi. This can be problematic due to the pollution of the environmental, the health hazards for human and animals and resistance of some strains to chemicals. Essential oils (EOs) have the potential to control these mycotoxigenic fungi due to their chemical components (Adukwu et al., 2016).

Furthermore, EOs are volatile compounds that are easily degraded when exposed to factors such as light, oxygen and temperature (Beyki et al, 2014); thus, affecting their stability, sensorial properties and functionality (de Lira-Mota et al., 2012; Soliman et al., 2013; Bakry et al., 2016). In order to maintain the EOs native structure, we have used chitosan to encapsulate it due to its chemical and physical properties. Chitosan also has antimicrobial and antifungal activity (Souza et al., 2014).
For this reason, the aim of this study was to evaluate the efficacy of GRAS cinnamon, clove and thyme essential oils (EOs) alone, and encapsulated in chitosan on the radial growth and spore germination in Fusarium verticillioides and Aspergillus parasiticus and in the production of mycotoxin.

\section{Materials and methods}

\subsection{Materials and preparation of chitosan microparticles}

We purchased essential oils of clove (Syzygium aromaticum), cinnamon (Cinnamomum zeylanicum) and thyme (Thymus capitatus) from Sigma Aldrich. We used low viscosity chitosan (CS) with a deacetylation degree of $<85 \%$ and molecular weight of $130 \mathrm{kDa}$.

For encapsulation of the EOs, we used the ionotropic gelation technique described by Cota-Arriola et al. (2013). We added $2 \mathrm{~mL}$ of each EO individually and sprayed $240 \mathrm{~mL}$ of $0.2 \%$ Sodium tripolyphosphate (TPP) in $80 \mathrm{~mL}$ of a $0.5 \%$ $(\mathrm{w} / \mathrm{v})$ chitosan solution in $0.1 \mathrm{M}$ acetic acid. The solution was stirred for $15 \mathrm{~min}$ at $500 \mathrm{rpm}$ and we obtained microparticles with each EOs encapsulated. 


\subsection{Gas chromatography-mass spectrometry (GC-MS) analysis}

Analyses of EOs were performed as described by Ayala-Zavala et al. (2008) using a Varian GC-3400 Cx with a Saturn 2100T mass-selective detector (Varian, Mexico) and a DB- 5 capillary column $(30 \mathrm{~m} \times 0.25 \mathrm{~mm}$, film thickness $0.25 \mu \mathrm{m})$.

\subsection{Microorganisms and culture conditions}

Pathogenic strains were Aspergillus parasiticus (ATCC 16992) and Fusarium verticillioides (ATCC 52539). A spore suspension was obtained from their respective 7 days old cultured in potato-dextrose agar (PDA), mixed in Tween $20(0.1 \%, \mathrm{v} / \mathrm{v})$ to obtain a homogeneous spore suspension of $1 \times 10^{5}$ spores $\mathrm{mL}^{-1}$.

\subsection{Preparation of culture medium with EOs}

Twenty-five $\mathrm{mL}$ of Tween 80 (1\%) was deposited in a $50 \mathrm{~mL}$ Falcon tube and the appropriate amount of each EOs to obtain 100, 500, 750 and $1000 \mathrm{ppm}$. Then, $25 \mathrm{~mL}$ of Czapek medium was poured in 5-cm Petri dishes. Positive control was the commercial fungicide Terravax ${ }^{\circ}$ (Captan 20\% + Carboxin 20\%) $2.5 \mathrm{~g} \mathrm{~L}^{-1}$. Other two controls were Tween 80 and Czapek alone.

\subsection{Preparation of culture medium with EOs-encapsulated microparticles}

In other Falcon tubes were deposited $25 \mathrm{~mL}$ of Czapek medium and the appropriate amount of each microparticles with the EOs encapsulated to obtain 100, 500, 750 and $1000 \mathrm{ppm}$. Controls were Czapek alone, Czapek - TPP $(0.2 \%, 7: 3)$ and chitosan (CS) (Czapek - CS (0.5\%, 7:3). All the experiment was conducted in triplicate.

\subsection{Zeta potential and size of the microparticles}

The zeta potential and size of the microparticles with $\mathrm{EO}$ was quantified using a Zetasizer Nano-25 (Malvern Instruments) at $25^{\circ} \mathrm{C}$. Each microparticles was dialyzed against $0.03 \mathrm{M}$ Tris buffer, pH 5.6 for $18 \mathrm{~h}$ in a $12 \mathrm{kDa}$ membrane (Liu \& Gao, 2009).

\subsection{Antifungal activity assay}

For radial growth, Petri dishes of solid Czapek media containing 100, 500, 750, and 1000 ppm of each EOs, dishes with the microcapsules and the controls were centrally point-inoculated with $1 \times 10^{5}$ spores $\mathrm{mL}^{-1}$ from 7-day-old cultures of F. verticillioides (ATCC 52539) or A. parasiticus (ATCC 16992). The dishes were incubated at $25^{\circ} \mathrm{C}$ using a $12 \mathrm{~h} \mathrm{light/dark} \mathrm{cycle}$ for F. verticillioides and $27 \pm 2{ }^{\circ} \mathrm{C}$ for Aspergillus. The colony diameter was measured daily with a caliper until the control reached the plate border. The EOs concentration that delayed $50 \%$ of colony radial extension $\left(\mathrm{CI}_{50}\right)$ was determined at $95 \%$ of confidence intervals, using a Probit analysis with NCSS 97 statistical program (NCSS Inc., U.S.A.). All determinations were conducted in triplicate. The radial growth inhibition compared to the control was calculated as a percentage using the Equation 1:

Radial inhibition $(\%)=\frac{\left(\bar{R}_{\mathrm{c}}-R_{\mathrm{i}}\right)}{\bar{R}_{\mathrm{c}}} \times 100$, where $\bar{R}_{\mathrm{c}}$ was the mean value of radius of colonies ( $\mathrm{mm}$ ) grown in Tween control and $R_{\mathrm{i}}$ was the colony radius of the EOs amended media.

The assay for spore germination was conducted using $2 \mathrm{~mL}$ Eppendorf tubes with liquid Czapek media containing $100,500,750$, and $1000 \mathrm{ppm}$ of each EOs, tubes containing the microcapsules with the $\mathrm{CI}_{50}$ obtained in the radial growth test and the amount of Tween $80(1 \%)$ needed to reach $1 \mathrm{~mL}$. Also, the above mentioned controls were included.

All the tubes were inoculated with $1 \times 10^{5}$ spores $\mathrm{mL}^{-1}$ from 7-day-old cultures of $F$. verticillioides (ATCC 52539) or A. parasiticus (ATCC 16992). Dishes were incubated at $25^{\circ} \mathrm{C}$ using a $12 \mathrm{~h}$ light/dark cycle for $F$. verticillioides and $27 \pm 2^{\circ} \mathrm{C}$ for A. parasiticus. A $10 \mu \mathrm{L}$ sample was taken at 3,9 , and $15 \mathrm{~h}$ after incubation from each tube, placed in a glass slide, covered and 100 spores were observed to evaluate germination by looking for the presence of the germ tube. A spore was considered germinated when its germinal tube reached one-half of the spore diameter (López-Meneses et al., 2015). Each germination assay was made in quadruplicate. The inhibition of spore germination was determined using the Equation 2:

Inhibition $(\%)=[(\% S c-\% S t) / \% S c] \times 100$

in which $S_{i}$ represents the percentage of germinated spores in the tubes treated with EOs or microcapsules, and $S_{c}$ was the percentage of germinated spores in the Tween control (López-Meneses et al., 2015).

\subsection{Evaluation of the effect of microparticles with EOs in mycotoxin production}

Sound corn grain was used for mycotoxin production. Fifty-grams of corn were cracked and placed in $250 \mathrm{~mL}$ Erlenmeyer flask, adjusted to $40 \%$ moisture by adding water and sterilized for two-consecutive days in autoclave. Autoclaved corn was treated with $10 \mathrm{~mL}$ of sodium acetate buffer $(0.03 \mathrm{M})$ and with the microcapsules with the $\mathrm{CI}_{50}$ of each EO. The flasks were inoculated with $1 \times 10^{5}$ spores $\mathrm{mL}^{-1}$ of $F$. verticillioides or A. parasiticus and incubated for 16 days at the above mentioned conditions. Four controls were prepared following the same procedure with no microparticles with EOs added: CS, water, and TPP with the inoculum and the fourth contained just $10 \mathrm{~mL}$ of water without inoculum. The extraction and quantification of fumonisin and aflatoxin was carried out according to Rosas-Burgos et al. (2011) and Cota-Arriola et al. (2011), respectively. Each treatment was replicated three times.

\subsection{Statistical analysis}

The data analysis was conducted by ANOVA using a factorial design (type of EO, concentration, and fungus). Comparison of means in homogeneous subsets was performed using the Tukey multiple comparisons test at $95 \%$ confidence interval employing the JMP version 5.0, NCSS, SigmaPlot 10.0 (Systat Software Inc., 2006). 


\section{Results and discussion}

\subsection{Chemical composition of essential oil}

The identified chemical composition and percentage composition of the EOs are shown in Table 1. The most abundant component of the thyme essential oil was 2-methyl-5-(1-methyethyl)phenol (46.2\%) whereas eugenol (70.0 and 63.0\%) was the main component in cinnamon and clove, respectively.

\subsection{Zeta potential of CS-TPP matrices with immobilized FA}

It is reported that the zeta potential or surface charge is an essential parameter in the characteristics of a particle, mainly through its influence on stability (Du et al., 2009) and determines the antimicrobial potential on fungi and bacteria (Cai et al., 2008). The zeta potential ( $\mathrm{mV}$ ) of the chitosan microparticles with tripolyphosphate and essential oils incorporated were $+38.5 \pm 0.9,+38.5 \pm 2.1,+29.6 \pm 0.2$ with size $(\mathrm{nm})$ of $775.2 \pm 291.6$, $788.0 \pm 96.8$, and $735.8 \pm 118.8$ for thyme, clove and cinnamon, respectively. The microparticles with cinnamon oil exhibited the lowest surface charges $(+29.6 \pm 0.2)$. This may indicate that not all of the amino groups from CS were loaded and could be due to amount of sodium tripolyphosphate added for the crosslinking (Liu \& Gao, 2009). The microparticles with clove and thyme EOs showed good surface charges, higher than $+30 \mathrm{mV}$, which indicates their amino groups are protonated and have more opportunity to interact with the fungus membrane affecting some of their functions. In addition, it has been reported that for a physically stable nanosuspension stabilized by electrostatic repulsion a zeta potential of $+30 \mathrm{mV}$ is required (Müller et al., 2001). The size of the three microparticles with EOs was similar, so their distribution might be not affected by this parameter.

Inhibition of $A$. parasiticus radial growth by EOs is presented in Figure 1. Fungi in Tween control required $144 \mathrm{~h}$ to spread entirely in the dish. The three EOs produced total inhibition at $24 \mathrm{~h}$ with doses higher than $500 \mathrm{ppm}$ but after this time, in treatment with 100 and 500 ppm, the effect was reduced, probably due to fungi adaptation to the EOs. There were significant differences ( $\mathrm{p} \leq 0.05)$ only among the concentrations.

Figure 2 shows data for F. verticillioides. Inhibition of germination was observed since $48 \mathrm{~h}$ of incubation with the three EOs. We observed that the three EOs are effective to inhibit the radial growth. Thyme was the only EO able to cause $60 \%$ of inhibition with the lowest concentration (100 ppm) tested. Inhibition by other oils and higher concentrations were effective the three times evaluated. There were significant differences ( $\mathrm{p} \leq 0.05)$ among the EOs and concentrations tested. Effects on the colonies were observed in both fungi, $A$. parasiticus and
F. verticillioides. Their aspect and texture was irregular in color and exhibited a cottony mycelium.

\subsection{Effect of the microcapsules in the radial growth}

Table 2 shows radial growth of $A$. parasiticus and F. verticillioides in presence of chitosan microcapsules with essential oil encapsulated. Inhibition of the radial growth of $A$. parasiticus begun at $48 \mathrm{~h}$ of incubation whereas for $F$. verticillioides it started at $24 \mathrm{~h}$. There was a statistical difference $(\mathrm{p} \leq 0.05)$ among the microcapsules with the essential oils and concentrations. Comparing the results for radial growth with EOs alone (Figures 1 and 2) and those from microcapsules, cinnamon oil caused the highest inhibition (90-100\%) of $A$. parasiticus and the microcapsules with clove oil (97-98\%). We were expecting high inhibition in all the treatments due to synergistic or additive effect among the antifungal activity of chitosan and the essential oils; however, inhibition by microcapsules was low compare to that caused by the essential oils alone. For $F$. verticillioides, microcapsules with thyme oil were statistically different $(\mathrm{p} \leq 0.05)$ (Table 2$)$, they produced low effect on radial growth. Studies by Cota-Arriola et al. (2013)

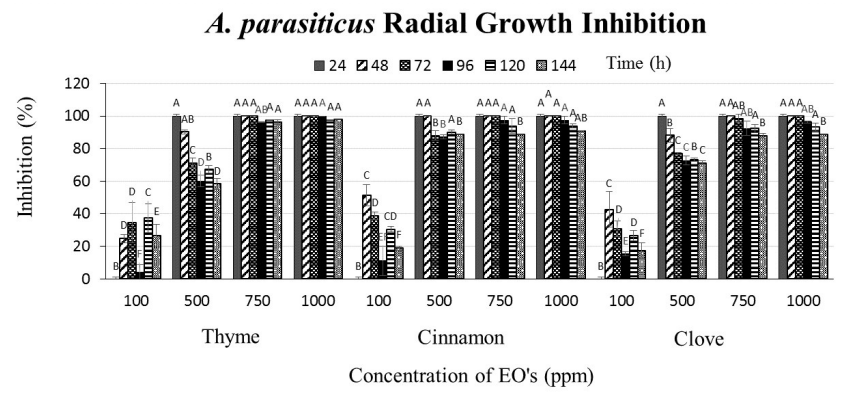

Figure 1. Inhibition of $A$. parasiticus radial growth (\%) by essential oils at different incubation times. Columns having different letters are significantly different according to Tukey test $(\mathrm{p} \leq 0.05)$.

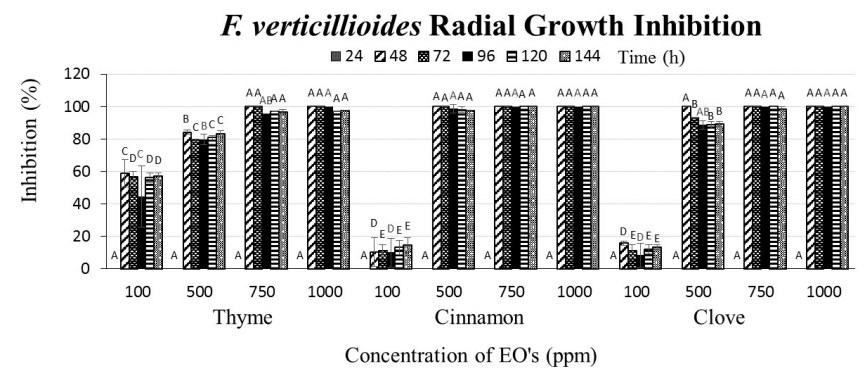

Figure 2. Inhibition of $F$. verticillioides radial growth (\%) by essential oils at different incubation times. Columns having different letters are significantly different according to Tukey test $(\mathrm{p} \leq 0.05)$.

Table 1. Chemical composition and percentage of the essential oils components.

\begin{tabular}{|c|c|c|c|c|c|}
\hline \multicolumn{2}{|l|}{ Thyme } & \multicolumn{2}{|c|}{ Cinnamon leaf } & \multicolumn{2}{|c|}{ Clove leaf } \\
\hline Compound & $\%$ & Compound & $\%$ & Compound & $\%$ \\
\hline 2-methyl-5-(1-methyethyl)-phenol & 46.2 & Eugenol & 70.0 & Eugenol & 63.0 \\
\hline Thymol & 13.6 & Caryophyllene & 4.5 & Caryophyllene & 17.0 \\
\hline o-Cymene & 12.0 & Benzylbenzoate & 2.8 & a-Humulene & 2.5 \\
\hline$\beta$-Pinene & 6.4 & $o$-Eugenol & 2.2 & Cadinene & 1.3 \\
\hline
\end{tabular}


Table 2. Inhibition of A. parasiticus and F. verticillioides radial growth (\%) by chitosan microcapsules with essential oils encapsulated.

\begin{tabular}{|c|c|c|c|c|c|c|}
\hline \multirow{3}{*}{ Treatment } & \multicolumn{3}{|c|}{ A. parasiticus } & \multicolumn{3}{|c|}{ F. verticillioides } \\
\hline & \multicolumn{6}{|c|}{ Incubation time (hours) } \\
\hline & 48 & 96 & 144 & 48 & 96 & 144 \\
\hline $\mathrm{C}_{\mathrm{Tw}}$ & $0^{g}$ & $0^{\mathrm{g}}$ & $0^{\mathrm{h}}$ & $0^{\mathrm{e}}$ & $0^{\mathrm{h}}$ & $0^{\mathrm{f}}$ \\
\hline \multicolumn{7}{|l|}{ Thyme } \\
\hline 100 & $14.5 \pm 11.4^{\mathrm{efg}}$ & $24.8 \pm 6.3^{\mathrm{e}}$ & $19.9 \pm 4.3^{\mathrm{fg}}$ & $0^{\mathrm{e}}$ & $0^{\mathrm{h}}$ & $0^{\mathrm{f}}$ \\
\hline 500 & $45.5 \pm 7.0^{\text {cde }}$ & $51.7 \pm 2.9^{c}$ & $37.9 \pm 3.4^{\mathrm{d}}$ & $17.8 \pm 14.5^{\mathrm{cd}}$ & $18.1 \pm 5.1^{\mathrm{f}}$ & $0^{\mathrm{f}}$ \\
\hline 1000 & $95.0 \pm 1.1^{\mathrm{ab}}$ & $87.4 \pm 0.1^{\mathrm{a}}$ & $78.7 \pm 2.7^{\mathrm{b}}$ & $64.5 \pm 3.8^{\mathrm{b}}$ & $51.4 \pm 3.1^{\mathrm{d}}$ & $32.4 \pm 4.7^{\mathrm{d}}$ \\
\hline \multicolumn{7}{|l|}{ Clove } \\
\hline 100 & $24.1 \pm 14.2^{\mathrm{defg}}$ & $26.6 \pm 4.4^{\mathrm{e}}$ & $25.9 \pm 3.7^{\mathrm{efg}}$ & $14.6 \pm 10.1^{\mathrm{de}}$ & $19.6 \pm 1.3^{\mathrm{fg}}$ & $0^{\mathrm{f}}$ \\
\hline 500 & $85.3 \pm 9.9^{\mathrm{ab}}$ & $72.7 \pm 3.7^{\mathrm{b}}$ & $56.1 \pm 4.1^{\mathrm{c}}$ & $42.3 \pm 8.7^{\mathrm{c}}$ & $55.1 \pm 2.5^{\mathrm{cd}}$ & $39.2 \pm 3.4^{\mathrm{cd}}$ \\
\hline 750 & $97.6 \pm 0.7^{\mathrm{a}}$ & $91.6 \pm 0.3^{\mathrm{a}}$ & $83.0 \pm 1.4^{\mathrm{ab}}$ & $64.7 \pm 18.3^{\mathrm{b}}$ & $69.6 \pm 1.7^{\mathrm{b}}$ & $56.3 \pm 2.9^{\mathrm{b}}$ \\
\hline 500 & $34.5 \pm 12.7^{\text {cdef }}$ & $40.4 \pm 3.6^{\mathrm{d}}$ & $30.1 \pm 3.0^{\mathrm{def}}$ & $32.9 \pm 8.4^{\mathrm{cd}}$ & $35.5 \pm 2.7^{\mathrm{e}}$ & $13.6 \pm 4.5^{\mathrm{e}}$ \\
\hline 750 & $50.9 \pm 4.8^{\mathrm{cd}}$ & $49.8 \pm 4.5^{c}$ & $34.9 \pm 4.0^{\mathrm{de}}$ & $64.3 \pm 5.1^{\mathrm{b}}$ & $60.1 \pm 2.6^{c}$ & $44.9 \pm 3.9^{c}$ \\
\hline 1000 & $61.0 \pm 10.5^{\mathrm{bc}}$ & $54.3 \pm 1.8^{c}$ & $49.4 \pm 5.3^{\mathrm{c}}$ & $86.5 \pm 2.4^{\mathrm{a}}$ & $78.3 \pm 3.8^{\mathrm{a}}$ & $69.3 \pm 2.9^{\mathrm{a}}$ \\
\hline
\end{tabular}

Different letters show significant differences $(P<0.05)$ between the treatments; $\mathrm{C}_{\mathrm{Tw}}=$ Control Tween.

and Plascencia-Jatomea et al. (2014) mentioned that chitosan had no fungicide effect on $A$. parasiticus and A. niger, findings that agree to ours. Both authors mentioned that these fungi have some type of adaptation to chitosan, probably due to the physiological stress provoked by the high production of chitinases and chitosanases to degrade the chitosan, allowing the fungi to use it as a source of energy. Furthermore, microcapsules with essential oils encapsulated were less effective to inhibit radial growth in both fungi compared with essential oils alone. This could be due to the low amount of TPP $(0.2 \%)$ added for preparation of chitosan microparticles. Some studies reported a higher amount of TPP and high inhibition of microorganism growth. Zhao et al. (2015) in their study to elaborate chitosan nanoparticles, added TPP (0.25\%), Du et al. (2009) TPP (1\%), Cota-Arriola et al. (2013) employed three amounts of TPP (2.0, 6.0 and 10.0\%), and Mohammadi et al. (2015) TPP (0.3\%). The $\mathrm{IC}_{50}$ of thyme, clove, and cinnamon EOs for A. parasiticus was $117.9,111.8$, and $156.1 \mathrm{ppm}$, respectively, whereas for F. verticillioides it was $67.7,154.6$, and $156.1 \mathrm{ppm}$, respectively. Moreover, we observed morphological changes in the colonies of both fungus developing on dishes treated with chitosan microcapsules. This agrees with the findings of Cota-Arriola et al. (2013), whose study reported changes in color of the colonies grown and mycelium formation in presence of chitosan micro and nanoparticles with TPP compared to those from the controls.

\subsection{Effect of essential oils in spore germination}

Figure 3 presents results on the effects of essential oils in A. parasiticus. The three essential oils at $500 \mathrm{ppm}$ and higher inhibited the spore germination since the $3 \mathrm{~h}$ of incubation in comparison to the controls. We observed a high inhibition percentage was observed after $9 \mathrm{~h}$ of incubation with all the

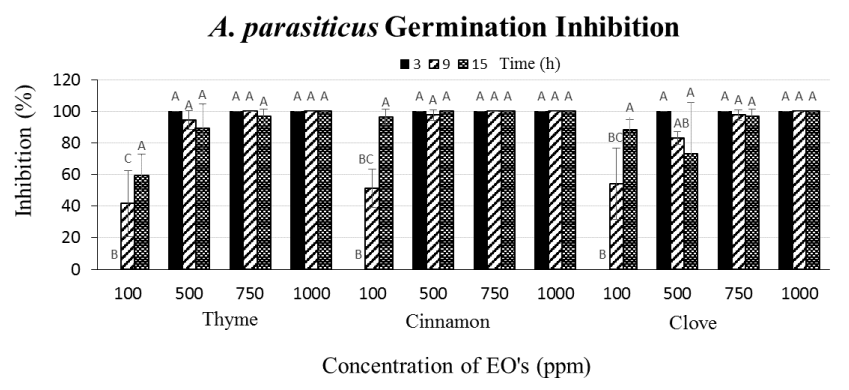

Figure 3. Inhibition of A. parasiticus spore germination by essential oils at different incubation times. Columns having different letters are significantly different according to Tukey test $(\mathrm{p} \leq 0.05)$.

EOs. The inhibitory effect of all EOs at $100 \mathrm{ppm}$ increased proportionally to the treatment duration (from $20 \%$ at $3 \mathrm{~h}$ up to $75-80 \%$ at $15 \mathrm{~h})$. There was statistical difference $(\mathrm{p} \leq 0.05)$ only among the concentrations.

Figure 4 shows F. verticillioides spore germination in presence of essential oils. Clove and cinnamon EOs caused the highest inhibition in all concentrations and incubation times. Total inhibition (100\%) was reached with concentrations of $500 \mathrm{ppm}$ and higher after $9 \mathrm{~h}$ of incubation. There were statistical differences $(\mathrm{p} \leq 0.05)$ among the concentrations and EOs. Study on essential oils in spore germination is limited, hence, the mechanism is not well known. Some authors have reported inhibitory effects and mentioned that the effect is due to inactivation of enzymes involved in the germination process and to depolarization of the mitochondrial membrane by diminishing the potential of membrane and affecting the $\mathrm{Ca}^{++}$ionic channels, which are crucial for spore germination (Kocevski et al., 2013; Bakkali et al., 2008). 
Table 3. Inhibition of $F$. verticillioides and A. parasiticus spore germination with chitosan microcapsules with $\mathrm{DI}_{50}$ of each essential oils encapsulated.

\begin{tabular}{lccccccc}
\hline \multirow{2}{*}{$\begin{array}{c}\text { Essential oil } \mathrm{DI}_{50} \\
(\mathrm{ppm})\end{array}$} & \multicolumn{3}{c}{ Fusarium verticillioides } \\
\cline { 2 - 7 } & 3 & 9 & 15 & $\mathrm{DI}_{50}$ & 3 & \multicolumn{4}{c}{ Aspergillus flavus } \\
\cline { 2 - 7 } & $0^{\mathrm{B}}$ & $0^{\mathrm{B}}$ & $0^{\mathrm{B}}$ & & $0^{\mathrm{C}}$ & $0^{\mathrm{C}}$ & $0^{\mathrm{B}}$ \\
$\mathrm{C}_{\mathrm{Cz}}$ & $100.0 \pm 0.0^{\mathrm{A}}$ & $0^{\mathrm{B}}$ & $0^{\mathrm{B}}$ & 118 & $100.0 \pm 0.0^{\mathrm{A}}$ & $65.5 \pm 1.7^{\mathrm{B}}$ & $77.6 \pm 15.4^{\mathrm{A}}$ \\
Thyme (67.7) & $83.3 \pm 23.6^{\mathrm{A}}$ & $76.0 \pm 1.4^{\mathrm{A}}$ & $0^{\mathrm{B}}$ & 156 & $75.0 \pm 35.4^{\mathrm{AB}}$ & $73.2 \pm 2.5^{\mathrm{A}}$ & $0^{\mathrm{B}}$ \\
Clove (156.1) & $83.0 \pm 23.6^{\mathrm{A}}$ & $0^{\mathrm{B}}$ & $31.9 \pm 9^{\mathrm{A}}$ & 112 & $77.6 \pm 15.6^{\mathrm{B}}$ & $0^{\mathrm{C}}$ & $62.5 \pm 20.3^{\mathrm{A}}$ \\
Cinnamon & & & & & & & \\
$(154.6)$ & & & & & & & \\
\hline
\end{tabular}

Values represent means made from three repetitions; Different letters show significant differences $(P<0.05)$ between the treatments; $\mathrm{C}_{\mathrm{C} z}$ : Control Czapek.

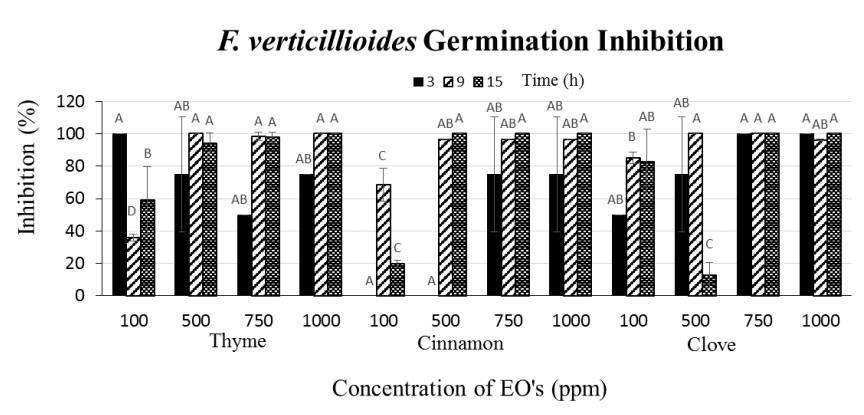

Figure 4. Inhibition of $F$. verticillioides spore germination by essential oils at different incubation times. Columns having different letters are significantly different according to Tukey test $(\mathrm{p} \leq 0.05)$.

\subsection{Effect of microcapsules in spore germination}

Results from the inhibition of $A$. parasiticus and $F$. verticillioides spore germination caused by microcapsules with the $\mathrm{CI}_{50}$ of each essential oil are shown in Table 3. There were statistical difference among the oils and concentrations. Spores of $A$. parasiticus were more sensitive to the different treatments than $F$. verticillioides. Plascencia-Jatomea et al. (2014) reported spores polarization in A. niger grown in solid and liquid Czapek medium amended with chitosan. They mentioned that the effects of chitosan varied proportionally according to the concentration and diminished with the incubation time. Additionally, they suggested that chitosan has fungistatic activity in $A$. niger, which could have happened in our study with $F$. verticillioides and $A$. parasiticus. This effect could be attributed to the chitosan chelating potential to calcium $\left(\mathrm{Ca}^{2+}\right)$, which is conferred by the free amino groups and hydroxyls present, or to the electrostatic interaction between the protonated amino groups $\left(\mathrm{NH}_{3}^{+}\right)$with components of the cellular membrane of the fungus such as phospholipids (Ali et al., 2010; Du et al., 2009).

\subsection{Effect of the microcapsules in mycotoxin production}

Table 4 shows the results of aflatoxin and fumonisin production in corn grain with microcapsules of chitosan with essential oils encapsulated. Mycotoxin production was low in grain treated with the microcapsules compared to those from controls. There were no statistical differences among the oils ( $p \geq 0.05)$. Chitosan alone significantly reduced $(\mathrm{p} \leq 0.05)$ the aflatoxin production. In a study of Velluti et al. (2003), cinnamon, clove and thyme oils caused significant reduction of fumonisin production in three
Table 4. Effect of chitosan microcapsules with $\mathrm{CI}_{50}$ of essential oils in aflatoxin and fumonisin production.

\begin{tabular}{ccc}
\hline Treatment & Aflatoxins $(\mathrm{ng} / \mathrm{g})$ & Fumonisins $(\mu \mathrm{g} / \mathrm{kg})$ \\
\hline $\mathrm{C}_{\mathrm{w}}$ & $1866 \pm 264^{\mathrm{A}}$ & $5.7 \pm 0.7^{\mathrm{A}}$ \\
$\mathrm{C}_{\mathrm{cs}}$ & $950 \pm 476^{\mathrm{B}}$ & $3.3 \pm 0.0^{\mathrm{B}}$ \\
$\mathrm{C}_{\mathrm{TPP}}$ & $2133 \pm 57^{\mathrm{A}}$ & $3.7 \pm 0.0^{\mathrm{B}}$ \\
Thyme & $1700 \pm 264^{\mathrm{AB}}$ & $3.5 \pm 0.3^{\mathrm{B}}$ \\
Clove & $1466.6 \pm 321^{\mathrm{AB}}$ & $3.3 \pm 0.3^{\mathrm{B}}$ \\
Cinnamon & $1833.3 \pm 57^{\mathrm{A}}$ & $3.8 \pm 0.3^{\mathrm{B}}$ \\
\hline
\end{tabular}

Data followed by the standard deviation are means from three replicates. Different letters show significant differences $(P<0.05)$ between the treatments. $\mathrm{Cw}$ (Control water), Ccs (Control chitosan) and $\mathrm{C}_{\mathrm{TPP}}$ (Control of sodium tripolyphosphate).

strains of F. proliferatum. In addition, chitosan alone has the ability to inhibit aflatoxin production due to the $\mathrm{Ca}^{2+}$ chelation. However, Cota-Arriola et al. (2011) found that this inhibition did not occurred in corn grain, probably because the polymer is not able to penetrate into the grain, and thus limiting the ability for calcium chelation.

\section{Conclusions}

Essential oils alone at doses of 500 ppm or higher are better to inhibit radial growth and spore germination of $A$. parasiticus and $F$. verticillioides than microcapsules with encapsulated EOs. We did not observe synergism or additive effect among essential oils and chitosan as we expect, even more, they showed less inhibition when encapsulated. Essential oils only have a fungistatic effect when applied pure or encapsulated in microparticles. Chitosan microcapsules with sodium tripolyphosphate reduced total production of aflatoxin and fumonisin by Aspergillus parasiticus and Fusarium verticillioides compared to control.

\section{Acknowledgements}

The study was funded by the Mexican Council for Science and Technology (CONACyT) through the project CB-2013-01 at the University of Sonora.

\section{References}

Adukwu, E. C., Bowles, M., Edwards-Jones, V., \& Bone, H. (2016). Antimicrobial activity, cytotoxicity and chemical analysis of lemongrass essential oil (Cymbopogon flexuosus) and pure citral. Applied 
Microbiology and Biotechnology, 100(22), 919-927. PMid:27562470. http://dx.doi.org/10.1007/s00253-016-7807-y.

Ali, S. W., Joshi, M., \& Rajendran, S. (2010). Modulation of size, shape and surface charge of chitosan nanoparticles with reference to antimicrobial activity.. Advanced Science Letters, 3(4), 452-460. http://dx.doi.org/10.1166/asl.2010.1152.

Ayala-Zavala, J. F., Soto-Valdez, H., González-León, A., ÁlvarezParrilla, E., Martín-Belloso, O., \& González-Aguilar, G. A. (2008). Microencapsulation of cinnamon leaf (Cinnamomum zeylanicum) and garlic (Allium sativum) oils in $\beta$-cyclodextrin. Journal of Inclusion Phenomena and Macrocyclic Chemistry, 60(3), 359-368. http://dx.doi. org/10.1007/s10847-007-9385-1.

Bakkali, F., Averbeck, S., Averbeck, D., \& Idaomar, M. (2008). Biological effects of essential oils: a review. Food and Chemical Toxicology, 46(2), 446-475. PMid:17996351. http://dx.doi.org/10.1016/j.fct.2007.09.106.

Bakry, A. M., Abbas, S., Ali, B., Majeed, H., Abouelwafa, M. Y., Mousa, A., \& Liang, L. (2016). Microencapsulation of oils: a comprehensive review of benefits, techniques, and applications. Comprehensive Reviews in Food Science and Food Safety, 15(1), 143-182. http:// dx.doi.org/10.1111/1541-4337.12179.

Beyki, M., Zhaveh, S., Khalili, S. T., Rahmani-Cherati, T., Abollahi, A., Bayat, M., Tabatabaei, M., \& Mohsenifar, A. (2014). Encapsulation of Mentha piperita essential oils in chitosan-cinnamic acid nanogel with enhanced antimicrobial activity against Aspergillus flavus. Industrial Crops and Products, 54, 310-319. http://dx.doi.org/10.1016/j. indcrop.2014.01.033.

Cai, D., Blair, D., Dufort, F. J., Gumina, M. R., Huang, Z., Hong, G., Wagner, D., Canahan, D., Kempa, K., Ren, Z. F., \& Chiles, T. C. (2008). Preparation, characterization and antibacterial properties against $E$. coli $\mathrm{K}_{88}$ of chitosan nanoparticle loaded copper ions. Nanotechnology, 19(8), 1-5. PMid:19436766. http://dx.doi. org/10.1088/0957-4484/19/8/085707.

Cota-Arriola, O., Cortez-Rocha, M. O., Ezquerra-Brauer, J. M., LizardiMendoza, J., Burgos-Hernández, A., Robles-Sánchez, R. M., \& Plascencia-Jatomea, M. (2013). Ultrastructural, morphological, and antifungal properties of micro and nanoparticles of chitosan crosslinked with sodium tripolyphosphate. Journal of Polymers and the Environment, 21(4), 971-980. http://dx.doi.org/10.1007/ s10924-013-0583-1.

Cota-Arriola, O., Cortez-Rocha, M. O., Rosas-Burgos, E. C., BurgosHernández, A., López-Franco, Y. L., \& Plascencia-Jatomea, M. (2011). Antifungal effect of chitosan on the growth of Aspergillus parasiticus and production of aflatoxin B1. Polymer International, 60(6), 937-944. http://dx.doi.org/10.1002/pi.3054.

Du, W. L., Niu, S. S., Xu, Y. L., Xu, Z. R., \& Fan, C. L. (2009). Antibacterial activity of chitosan tripolyphosphate nanoparticles loaded with various metal ions. Carbohydrate Polymers, 75(3), 385-389. http:// dx.doi.org/10.1016/j.carbpol.2008.07.039.

Kocevski, D., Du, M., Kan, J., Jing, C., Lačanin, I., \& Pavlović, H. (2013). Antifungal effect of Allium tuberosum, Cinnamomum cassia, and Pogostemon cablin essential oils and their components against population of Aspergillus species. Journal of Food Science, 78(5), M731-M737. PMid:23647469. http://dx.doi.org/10.1111/17503841.12118 .

Lira-Mota, K. S., de Oliveira-Pereira, F., de Oliveira, W. A., Lima, I. O., \& de Oliveira-Lima, E. (2012). Antifungal activity of Thymus vulgaris
L. essential oil and its constituent phytochemicals against Rhizopus oryzae: interaction with ergosterol. Molecules, 17(12), 14418-14433. PMid:23519243. http://dx.doi.org/10.3390/molecules171214418.

Liu, H., \& Gao, C. (2009). Preparation and properties of ionically crosslinked chitosan nanoparticles. Polymers for Advanced Technologies, 20(7), 613-619. http://dx.doi.org/10.1002/pat.1306.

López-Meneses, A. K., Plascencia-Jatomea, M., Lizardi-Mendoza, J., Rosas-Burgos, E. C., Luque-Alcaraz, A. G., \& Cortez-Rocha, M. O. (2015). Antifungal and antimycotoxigenic activity of essential oils from Eucalyptus globulus, Thymus capitatus and Schinus molle. Food Science and Technology, 35(4), 664-671. http://dx.doi. org/10.1590/1678-457X.6732.

Mohammadi, A., Hashemi, M., \& Hosseini, S. M. (2015). Nanoencapsulation of Zataria multiflora essential oil preparation and characterization with enhanced antifungal activity for controlling Botrytis cinerea, the causal agent of gray mould disease. Innovative Food Science \& Emerging Technologies, 28, 73-80. http://dx.doi.org/10.1016/j. ifset.2014.12.011.

Müller, R. H., Jacobs, C., \& Kayser, O. (2001). Nanosuspensions as particulate drug formulations in therapy. Rationale for development and what we can expect for the future. Advanced Drug Delivery Reviews, 47(1), 3-19. PMid:11251242. http://dx.doi.org/10.1016/ S0169-409X(00)00118-6.

Plascencia-Jatomea, M., Yépiz-Gómez, M. S., \& Velez-Haro, J. M. (2014). Aspergillus spp. (Black mold). In S. Bautista-Baños (Ed.), Postharvest decay: control strategies (pp. 267-286, chap. 8). London: Elsevier.

Rosas-Burgos, E. C., Cortez-Rocha, M. O., Plascencia-Jatomea, M., Cinco-Moroyoqui, F. J., Robles-Zepeda, R. E., López-Cervantes, J., Sánchez-Machado, D. I., \& Lares-Villa, F. (2011). The effect of Baccharis glutinosa extract on the growth of mycotoxigenic fungi and fumonisin B1 and aflatoxin B1 production. World Journal of Microbiology \& Biotechnology, 27(5), 1025-1033. http://dx.doi. org/10.1007/s11274-010-0547-8.

Systat Software Inc. (2006). SigmaPlot 10.0: user's guide. Point Richmond: Systat Software.

Soliman, E. A., El-Moghazy, A. Y., El-Din, M. M., \& Massoud, M. A. (2013). Microencapsulation of essential oils within alginate: formulation and in vitro evaluation of antifungal activity. Journal of Encapsulation and Adsorption Sciences, 3(01), 48-55. http://dx.doi. org/10.4236/jeas.2013.31006.

Souza, J. M., Caldas, A. L., Tohidi, S. D., Molina, J., Souto, A. P., Fangueiro, R., \& Zille, A. (2014). Properties and controlled release of chitosan microencapsulated limonene oil. Revista Brasileira de Farmacognosia, 24(6), 691-698. http://dx.doi.org/10.1016/j.bjp.2014.11.007.

Velluti, A., Sanchis, V., Ramos, A. J., Egido, J., \& Marin, S. (2003). Inhibitory effect of cinnamon, clove, lemongrass, oregano and palmarose essential oils on growth and fumonisin B1 production by Fusarium proliferatum in maize grain. International Journal of Food Microbiology, 89(2-3), 145-154. PMid:14623380. http://dx.doi. org/10.1016/S0168-1605(03)00116-8.

Zhao, Z., Liu, N., Yang, L., Wang, J., Song, S., Nie, D., Yang, X., Hou, J., \& $\mathrm{Wu}, \mathrm{A}$. (2015). Cross-linked chitosan polymers as generic adsorbents for simultaneous adsorption of multiple mycotoxins. Food Control, 57, 362-369. http://dx.doi.org/10.1016/j.foodcont.2015.05.014. 